\title{
A review on contagious caprine Pleuro- pneumonia disease in small ruminants; sheep and goats
}

\author{
Abdul Kabir ${ }^{1}$, Amjad Hussian Mirani ${ }^{2}$, Muhammad Rasheed ${ }^{3}$, Deepesh \\ Kumar Bhuptani ${ }^{5}$, Hubdar Ali Kaleri ${ }^{6}$, Raj Kumar ${ }^{4}$, Muhammad Bakhsh \\ Abro $^{2}$, Moolchand Khatri ${ }^{1}$, Zakir Hussain Bozdar ${ }^{6}$, Abdul Wahid \\ Solangi ${ }^{6}$, Saqib Kakar ${ }^{6}$, Imam Bux Kandhro ${ }^{2}$ and Rameez Raja Kaleri ${ }^{6 *}$ \\ 1. Department of Veterinary Microbiology, Faculty of Animal Husbandry and Veterinary Sciences, SAU, Tandojam, \\ Pakistan \\ 2. Department of Veterinary Medicine, Faculty of Animal Husbandry and Veterinary Sciences, Sindh Agriculture \\ University, Tandojam, Pakistan \\ 3. Animal Science Institute, PARC- National Agriculture Research Center Islamabad, Pakistan \\ 4. Adamjee Government Science College, Karachi \\ 4. Department of Meat Technology, SBBUVAS, Sakrand, Pakistan \\ 6. Department of Animal Breeding \& Genetics, Faculty of Animal Husbandry and Veterinary Sciences, Sindh \\ Agriculture University, Tandojam, Pakistan \\ *Corresponding author's email: rameezkaleri@gmail.com
}

Citation

Abdul Kabir, Amjad Hussian Mirani, Muhammad Rasheed, Deepesh Kumar Bhuptani, Hubdar Ali Kaleri, Raj Kumar, Muhammad Bakhsh Abro, Moolchand Khatri, Zakir Hussain Bozdar, Abdul Wahid Solangi, Saqib Kakar, Imam Bux Kandhro and Rameez Raja Kaleri. A review on contagious caprine Pleuro-pneumonia disease in small ruminants; sheep and goats. Pure and Applied Biology. Vol. 11, Issue 2, pp536-547. http://dx.doi.org/10.19045/bspab.2022.110053

\begin{tabular}{llll}
\hline \hline Received: 00/05/2021 & Revised: 00/07/2021 & Accepted: 00/07/2021 & Online First: 26/08/2021
\end{tabular}

\section{Abstract}

Contagious Caprine Pleuropneumonia (CCPP) is most serious disease of goats. It is characterized by the elevated up to (100\%) morbidity rate and $(60 \%)$ mortality. The disease is caused by the subspecies capripneumoniae of Mycoplasma capricolum bacteria. This organism found throughout the world, in more than 40 countries, CCPP affects goats, pretense a significant the threat of goat farming all over the world. Common symptoms of CCPP are elevated fever $\left(41\right.$ to $\left.43^{\circ} \mathrm{C}\right)$, depression, reluctant to walk, dyspnea, lethargy, inability towards feed, painful open mouth breathing, coughing, stringy salivation, nasal discharge, grunting and death of uncovered animals within 5 days. It is reported that CCPP is not characterized a molecular zoonotic disease, but there are some serological test are available to diagnose it. Recently some detection associated test is performed like PCR for antibody rapid identification, latex agglutination test and pen side are also available for antibody detection. It is stated that due to lack of veterinary service availability and information about continuous surveillance of this disease at this time, we hope by the 2030 world may be eradicate such type of goat and sheep disease including CCPPP and PPR Peste Des Petitis Ruminant. Moreover, it is concluded that further studies on antibiotic sensitivity and exploration of novel antibiotics can help in better therapeutic management besides menace of antibiotic resistance. Re-visiting conventional prophylactic measures focusing on developing novel strain-based or recombinant vaccines using specific antigens (capsular or cellular) should be the most important strategy for controlling the disease worldwide.

Keywords: CCPP; Disease; Small ruminant; Sheep; Goat 


\section{Introduction}

CCPP is a highly one of the most infectious goat respiratory diseases. Animals who are infected animals get very ill, and the majority of them die. The bacteria Mycoplasma capricolum subspecies capripneumoniae causes the illness. Identical to that, two species, M. Subsp. subsp. Mycoides. Mycoides. M. Capri, and. Subsp. subsp. Mycoides. Mycoides. In small ruminants that resemble CCPP, Great-Colony Mycoids can cause a disease. But it happens even less frequently and has very distinct symptoms. CCPP is found in Africa, Asia, and the Middle East, but it has never been discovered in North America. As indicated by the term, in infected goats, CCPP causes serious respiratory disease. Symptoms of the disease may be very high fever $\left(41^{\circ} \mathrm{F} 43^{\circ} \mathrm{C}\right)$, lethargy, inability to eat, aggressive coughing, and trouble breathing. A frothy nasal discharge and stringy saliva may have affected animals. Death normally happens within 7 to 10 days, but it can take as long as 2 to 3 days. With a recurrent cough, nasal discharge and debilitation, some animals may have longterm infection. The illness is always fatal; mortality rates can be as high as $80 \%$ in herds. The dynamics of disease are checked annually by national and international researchers and agencies and the reputation for keeping an eye this new transnational challenge threat threatens naive goat populations from the surrounding contaminated herds of neighboring and mutually cooperative in various disease-free countries [1].

\section{Economic losses}

CCPP is cautious, being among the most common dangerous besides highly infectious goat diseases. Goat-producing countries, especially in the Middle East, Africa, and Asia, this result in severe economic losses [2]. In almost 40 countries, the disease is one of the mycoplasmal contaminations that lead to severe losses and can be as high as $100 \%$ in morbidity and mortality, especially in races with exotic animals. [2, 3]. The $100 \%$ morbidity and $80 \%$ mortality in simple and native herds. The CCPP's gross annual price in the endemic zones is projected to be approximately US\$507 million, resulting in significant monetary losses. Morbidity, death, and a decline or loss of production are all examples of economic losses efficiency to add complex costs of prevention, monitoring and care to [4]. In animal management, morbidity induces restrictions, burdens the cost of trade or transportation, and imposes restrictions on it. The loss of loved animals to death triggers mortality. Infected in developed countries, animals are usually culled. In both developed and developing countries, this is not possible nations [5].

\section{Risk of study with neighboring countries}

According to $[9,10]$, neighboring countries including, Iran, Afghanistan, India and China are more susceptible to this disease after outbreak in Pakistan. Not only these neighboring countries are on risk but Pakistan is also on the target of CCPP if any one of our neighbor country is going to be affected by the outbreak of this sever disease of sheep and goat.

\section{History}

Contagious caprine pleuropneumonia (CCPP) was first reported in 1873 as a destructive goat disease in Africa [6]. A century later, in Kenya in 1976, the causative agent was isolated from the lungs of goats [7]. It is a disease identified by the World Organization for Animal Health (OIE) that causes goat producers to suffer huge economic losses [8]. Capricolum mycpolasma subsp. The causative agent of CCPP is capripneumoniae (Mccp). This agent was identified previously as Mycoplasma sp. Form F38 and affects some wild ruminants of 2 [9]. It is a respiratory disease that is extremely infectious and dangerous. It is characterized by nasal discharge cough, extreme respiratory 
distress, difficult to walk, elevated morbidity (80-100 percent) and eventually spreads the disease to the entire flock. Mortality is also very high in the absence of care and can exceed $60-80 \%$ [10]. The necropsy lesions are primarily fibrinous pleuropneumonia with unilateral hepatization and strawcolored pleural fluid accumulation [11].

\section{Etiology of contagious caprine pleuropnemonia}

In the late 19th century, CCCP was first identified [12] and CCPP Mycoplasma capricolum subsp. caused the infection. A member of the Mycoplasmataceae family, capripneumoniae (formerly Mycoplasma biotype F-38) [13, 14]. Mccp has been recognized as a member of the cluster of Mycoplasma mycoides, which includes $\mathbf{M}$. Subsp. Mycoides. SC Mycoid (MmmSC), M. Subsp. Mycoides. LC Mycoid (MmmLC), M. Subsp. Mycoides. (Mmc) Capri, M. Subsp capricolum. Capricolum and Mycoplasma bovine group 7 ( $\mathrm{Bg} \mathrm{7}$ ) bacteria, a bovine isolate linked to ruminant disease (Pettersson et al., 1998). It was confirmed that these clusters of Mycoplasma mycoides date back around 10,000 years ago, and it was also suggested that the cluster be recognized and distributed according to livestock domestication [15].

\section{Geographic distribution}

In 20 nations, Mccp has been isolated, mainly due to its fastidiousness in culture. But, almost 40 African and Asian countries clinical details have been written. North, Central, and East Africa, as well as Asia, are all part of the Arabian Peninsula, the disease is present, but its borders remain unclear [16]. A much broader spread of CCPP from the recognized geographical region can be proposed when considering the infectious nature of the disease and the movements of pastoral goat flocks [17]. The countries in which the disease was identified, the countries in which the etiological agent was detected by means of a molecular test and the countries in which it was isolated are indicated. The arrow suggests that the disease was present in Mauritius, where Mccp was isolated in 2009.

\section{Epidemiology}

F38's taxonomic status has been a mystery for a long time, and it wasn't until 1993 that it was recognized as a subspecies of $\mathrm{M}$. M. capricolum subsp. capricolum capripneumoniae is a form of capripneumoniae that affects the lungs [18]. Mollicutes are divided into five classes. Phylogenetic analysis of $16 \mathrm{~S}$ rRNA sequences identified one of which, the $M$ is found in the spiroplasma group. c. capripneumoniae is a subgroup of capripneumoniae. within the letter $\mathrm{M}$ cluster of mycoides. Six essential ruminant mycoplasmas are found in this cluster, including M. m. M. mycoides SC, the cause of contagious bovine pleuropneumonia, $\mathrm{M}$. mycoides SC, M. mycoides SC, M. mycoides SC, M. mycoides SC, M. m. M. mycoides and L. mycoides $\mathrm{m}$. capri have immunological and biochemical properties in common.

\section{Host range}

CCPP has been known to affect only domestic goats for a long time [12]. At present, the danger of wild ungulates is highly concerned for zoos and for the maintenance of certain endangered species exposed to goats, both in their normal habitat and in jail [8]. In sheep in contact with affected goats, clinical disease and seropositivity have been described, so the portion of sheep as reservoirs of infection is unclear [19]. In the event of CCPP, farm clinical signs of respiratory was infected observed $70 \%$ of goats tested positive, but none of the sheep or calves tested positive. Thoracic lesions typical of CCPP have been developed entirely by goats. Mccp is a virus found in goats and sheep. It is stated that sheep may be the carrier of the causative agent. Some reports label Mccp's isolation 
from sheep due to Eritrea's respiratory condition [20] it was confirmed that sick sheep mixed with goats were suffering from respiratory disease [21]. In the Ethiopia region, through the investigation of the acute respiratory disease outbreak of sheep and goat in 2002, the CCPP causative agent was isolated from goat but not sheep. The investigators suspected that with their clinical presence in an outbreak of sheep, the organism could have been complex [22]. Ethiopian sheep showed no clinical signs of CCPP, but Mccp was isolated from actually healthy sheep that may show the Sheep's function as a reservoir for infection CCPP also reported Tanzanian sheep with a positive serotype [23], India [24].

\section{Clinical Sign}

High rates of morbidity (80-100\%) and mortality $(60-80 \%)$ at any age or sex can affect the two goats [25]. The incubation period is normally 10 days long, but it can be anything between 2 and 28 days long. The respiratory system is confined to clinical effects [26]. The first symptoms, usually 41$43^{\circ} \mathrm{C}$, are reluctance to walk and the onset of fever [27]. Breathing speeds up and becomes painful after 2-3 days of high fever, grunting with aggressive episodes of coughing. In pregnant goats, animals stand with abducted limbs, neck extended and abortions occur [28]. Continuous salivation occurs and a mucopurulent discharge blocks the noses. In the terminal phases, the Mouth-breathing, tongue protrusion, and frothy salivation render goats immobile, and death is swift. Symptoms of coughing are milder in subacute or chronic forms, and generally only apparent after exercise. In infants, where the outcome of death is typical, high mortality can be seen [29].

Wild ruminants have similar clinical symptoms to goats, emaciation, abundant serous and mucopurulent nasal discharge, reluctance to exercise, as well as a pathological lesion on the surface exclusively located in the lungs extreme partially hepatic. It has been confirmed that pleuropneumonia has occurred. On Arabians, in addition to the yellowish fibrin deposits and intense lung consolidation, the interlobular septum thickened, pleuritis developed, and an accumulation of straw-colored pleural fluid solidified to form a gelatinous coating on the lung of the infected antelope [30].

\section{Gross pathology}

The incidence and pathogenicity of Mycoplasma disease are also affected by the presence of other species in the same infection [26]. Pneumonia and serofibrin pleuritis with straw-colored fluid in the thorax may be unilateral or bilateral are distinguished by acute illness. Injuries caused by infectious caprine pleuropneumonia in the respiratory system are minimal [31]. The lung is granular on the cut surface with ample straw-coloured exudate. The lungs can contain pea-sized, yellow nodules, there are pockets of congestion around these nodules. Various Lung consolidation or necrosis can be seen, as well as swollen regional (bronchial) lymph nodes. Recurrent pleuropneumonia or persistent pleuritis, with acute encapsulation of lesions and multiple attachments to the chest wall, affects some long-term survivors [32]. Domesticated goats' interlobular septa do not normally thicken. Similar lesions can be found in wild CCPP ruminants, but some species have been identified with interlobular septal [33].

Wide-spread lesions have been identified organs of the body. The pericardial and peritoneal sacs were used to extract fluid from Serosinguine [34]. An accumulation of exudate in the trachea's lumen has congested it. There may be necrotic in size focal points and haemorrhages on the liver surface. With pus in the pelvis area, the kidneys are slightly swollen. In certain animals suffering from diarrhea, hemorrhages of the intestine with increased mesenteric lymph nodes are often observed [29]. In outbreaks of disease caused 
by Mccp, MmLC and MmSC, the knee joints in children are only affect on small scale and inflammation occur, while mastitis can only be seen in in adult animals [32].

\section{Histopathology}

In CCPP infections histopathological lesions caused by Mccp are limited to the respiratory tract only [33]. In the case of a tracheal lesion, the degradation infiltrated the lining epithelium by polymorphic cells with a nucleus was present. Bleeding of hyperactive mucous secretion cells are also found in the muscular layer [32]. Interstitial and bronchopneumonia emphysema and atelectasis were seen in the lung parts of the animals. Centered abscesses are surrounded by a fibrous heart infiltrated with chronic inflammatory cells in chronic cases. With perivascular leukocytic cell cuffing, thrombosis occurs in the microvasculature [34]. The lesions were limited to the thoracic cavity only in ccpp infection caused by Mccp. However, in Mmc infection, widespread lesions were discovered [25]. The area of congestion around the central veins and the area of necrosis in the parenchymal regions of the liver are often seen. The heart was found to be average in both scale and the pericardial sac of most animal's accumulated yellow tinged fibrinous fluid. The kidneys were normal in size, but a few instances had slightly congested kidneys with necrotic focal points. There was pus when incision was administered in the pelvis region [35]. With leukocyte infiltration in the sub mucosa, the intestine's villi and lining epithelium have sloughed off, and there are hemorrhages [33, 34].

\section{Contagious caprine pleuropneumonia transmission}

The disease is contagious and spreads quickly between animals through oculonasal discharge and wound excretion, urine and faces, as well as open joints [36]. Certain outbreaks have occurred in endemic areas where stable goats have been introduced into flocks [37]. The disease is readily contagious and for successful transmission by coughing, a short period of contact is required [27] and [37]. There is no evidence of indirect interaction, as the organism is extremely fragile in the atmosphere [27]. It is quickly inactivated at $60^{\circ} \mathrm{C}$ in 2 minutes, but it can live for more than 10 years in frozen polluted pleural fluid [37]. After heavy rains and longdistance transport of livestock, outbreaks of the disease also occur. (OIE 2009), Bad conditions in the atmosphere and primary infections [27]. At a concentration of 0.05 percent, formaldehyde will inactivate Mccp within 30 s. A 1.0 percent phenol solution will inactivate the organism within 3 minutes [37].

\section{Diagnosis}

High mortality and typical early thoracic injury in goats are considered to be highly predictive of Mccp infection in outbreaks of classical acute CCPP [27, 38]. However, depending on clinical signs and postmortem analysis alone, the diagnosis of Mycoplasma pneumonia cannot be entirely achieved. Additional laboratory tests are recommended to be performed in all cases of caprine mycoplasmosis to establish a presumed diagnosis [27]. It has been defined that the general principles for laboratory diagnosis of Mycoplasma mainly include,

1) Methods for direct microscopic demonstration in the host tissues or excreta of Mycoplasma cells and antigens,

2) Methods for Mycoplasma isolation and development from suspected tissues, and

3) Techniques for the identification and classification by determination

Of biochemical characteristics and/or serological typing of Mycoplasma isolates [39].

Confirmatory diagnosis of CCPP is accomplished by isolation and detection of the Mccp, although it is very difficult and time consuming to carry out precise tests required to classify the Mycoplasma. 
Mycoplasma capripneumoniae is fastidious, grows slowly in the broth medium, and on solid media only produces minute colonies. In addition, other common mycoplasmas, such as $\mathrm{M}$, are sometimes overgrown. To ovipneumoniae [27] capripneumoniae infection has been reported to have been largely hindered by difficulties in isolating the body from clinical material. Once the mycoplasma has been isolated as a causative agent, tests for immunofluorescence or growth or metabolic inhibition can be used to classify it. For the detection of Mccp antibodies, many laboratory serological tests can also be used, although serological cross reactions 11 can occur, particularly complement fixation (CFT) lacking specificity. Passive hemaglutination is another serological test; passive hemaglutination (PH) [40], The ELISA competitive test with unique monoclonal antibodies [41] and the latex agglutination test, which has been stated to be a very convenient field test for the detection of antibodies in whole blood or serum $[42,43]$. To significantly improve Mccp detection, molecular based tests such as Polymerized Chain Reactions (PCR) have been published [16]. Specific polymerase chain reaction (PCR) assays [44], When introduced, due to cross-reactions that occurred between the Mycoplasma mycoides family, shortcomings in laboratory diagnosis will be addressed as all members of this cluster share similar biochemical and serological properties. Mccp reverse DNA sequence analysis has been successfully used to research Mccp strain genetic diversity [45].

\section{Prevention and control}

Vaccines are of primary importance for the prevention and management of mycoplasmosis by the use of mollicute strains, which are either locally or generally prevalent. As early as 1950 in India, vaccine production for CCPP was attempted [46]. Novel strain-based or recombinant vaccines using specific antigens (capsular or cellular). Few experimental attempts have been made to improve the goat vaccine for caprine pleuropneumonia. These experimental vaccines have been tested from time to time against caprine pleuropneumonia [47]. But it is still important to research the larger goat population. There is currently no commercial vaccine available in India to combat morbidity and loss of mortality in goats against major mycoplasmal diseases, including caprine pleuropneumonia.

However, in various nations, the disease still exists. Therefore, different measures for the improvement of small ruminants, especially goats, have been taken. There are many goataffecting diseases that have gained significance for CCPP in the recent past due to its regular incidence and tremendous economic loss. In the 1990s, attempts were made to create mycoplasma vaccines. [48] A preliminary investigation was performed into the production of the killed caprine pleuropneumonia vaccine in goats. Lyophilized Mycoplasma capricolum subsp. vaccine. In African countries, capripneumoniae was found to be successful in producing protective immunity against CCPP in goats, as it was able to provide protection for a period of 12 months. [49] In goats immunized with killed Mycoplasma mycoides subsp, humoral response was tested. Slide agglutinatioin and latex agglutination experiments with capri saponin vaccine [50]. The immunogenicity of the Mycoplasma agalactiae saponin vaccine has been studied in mice. Since mycoplasma is a natural inhabitant of the ovine and caprine respiratory tract and causes diseases only under stressful conditions such as adverse environment, nutrient deficiency, overcrowding and immunosuppression, better management interventions may therefore be beneficial for prophylactic regimes [51, 52]. 


\section{Treatment}

Mccp has been treated with a variety of antibiotics to treat CCPPP $[51,53]$. The antiMccp drug of choice, however, is considered to be macrolides, particularly tylosin. In areas where CCPP is prevalent, tylosin is usually rarely available. The effectiveness of oxytetracycline in the treatment of CCPP has been demonstrated to be While it is successful and has been in use for a long time, long-term use in most areas is not recommended in addition to the risk of antibiotic resistance, side effects predispose (goat teratogenicity children) with an additional risk of prophylactic use allowing mycoplasma to cope better with antibiotics in limited doses. with an additional risk of prophylactic use allowing mycoplasma to cope better with antibiotics in limited doses. While other antibiotics such as Aminoglycosides (enrofloxacin, danofloxacin) and fluoroquinolones (enrofloxacin, danofloxacin) (streptomycin) and pleuromutilline (tiamulin) are being used and newer antibiotics on whom an investigation is underway Mccp among these classes, important determinants are the expense, availability, duration of action and convenience of the use and creation of carrier status and the use Antibiotics are commonly used in CCPP regions.

For the treatment of CCPP, earlier combinations each intramuscular dose, 30 $\mathrm{mg} / \mathrm{kg} \mathrm{BW}$ of dihydrostreptomycin sulphate with penicillin $G$ procaine was used. At single doses of $20,30,40$, or $50 \mathrm{mg} / \mathrm{kg} \mathrm{BW}$, dihydrostreptomycin sulphate was able to cure goats intramuscularly without forming carriers. Streptomycin cured CCPP-infected goats on day 3 in both natural and experimental infections, and treated goats developed full immunity to Mccpp [42]. The goats were then given oxytetracycline or tylosin after being inoculated with CCPP.Which decreased severity but remained contagious by 20 percent. Short- acting oxytetracycline and tylosin were given intramuscularly at 10 and $20 \mathrm{mg} / \mathrm{kg} \mathrm{BW}$ for 6 days, respectively, and a single dose of long-acting oxytetracycline was given intramuscularly at $20 \mathrm{mg} / \mathrm{kg} \mathrm{BW}$ for 6 days. Danofloxacin showed good efficacy in clinical CCPP cases when administered subcutaneously at 48-hour intervals at 6 $\mathrm{mg} / \mathrm{kg} \mathrm{BW}$ [54]. Long-acting oxytetracycline has helped to control the CCPP epidemic by preventing illness and deaths [55]. Tiamulin, especially in the early stages of the disease, has been considered one of the CCPP treatments [56, 57], However, due to a lack of field availability, it was only used sporadically. The efficacy of antibiotics in Mccp was evaluated over time for better use in CCPP and to avoid the emerging risk of antibiotic resistance.

The antibiotic sensitivity test (AST) in resistant mycoplasma mutants (M. bovis) included oxytetracycline $(>32)$, enrofloxacin (2.5-32), tylosin (8-1024), and florfenicol 2.3-6, tylosin (1.3-6.6), ceftiofur (0.8-1.2), and sulphamonomethoxine (2.3-7.3) Separates from others. Lomefloxacin, erythromycin (1.7-6.7) (3.3-6.7) Cluster region isolates of Mycoplasma mycoides [58]. Some older but often used antibiotics, such as tetracycline and tylosin, are thought to be beneficial when used early in infected herds [59]. Where they suspect opposition.Mccp strains are currently susceptible to a broad variety of groups of antibiotics, including macrolides, lincosamides, streptogramins, tetracyclines, and fluoroquinones. However, several strains have been identified that are immune to tetracyclines, erythromycin or streptomycin [53]. Indicating the potential for possible antibiotic resistance if sufficient steps are not taken. Alternating antibiotics is a better choice in places where there is little or less chance of not using antibiotics [53]. In terms of animal recovery, therapeutic parameter development, and clinical and pathological 
symptom resolution, tylosin showed Better performance than oxytetracycline, with enrofloxacin leading the way. Tylosin, however, is seldom made available in this region to farmers. Although When given to pregnant goats, oxytetracycline produced comparable results and showed prophylactic effects against CCPP; however, it caused deaths and deformities in some cases, which may be due to widespread use over decades due to ease of availability and lack of awareness of side effects. Enrofloxacin has been very effective and readily available, but has not been used in this trans-Himalayan mountainous area in the past, under field conditions Long-term usage, particularly in pregnant animals, should be considered, in addition to the Enrofloxacin side effects include bone abnormalities in newborns. Nomadic herdsmen chose long-acting antibiotic formulations not only because of their long action, but also because of their ease in giving a single injection, which also minimizes labor and expenses. Treatment based on antibiotics offers a temporary form of relief, but minimum use of antibiotics should be exercised for better clinical exploration and prevention of the danger of antibiotic resistance and, where not possible, AST should be required before use. For example, if the use of antibiotics is inevitable in remote livestock rearing areas in Asia and Africa, alternative effective antibiotics may be adopted. However, vaccine prevention is easier to reduce regular and large-scale use of antibiotics and immense clinical costs.

\section{Conclusion}

CCPP is a cross-border disease that poses a major threat to the livelihoods of goat farmers. CCPP can spread, regardless of national borders, and inflict significant socioeconomic harm due to its high morbidity and mortality. It is thus included in the OIE's list of notifiable diseases. And there is an urgent need to boost CCPP's awareness of veterinary facilities, testing policymakers in impacted and suspect areas, as well as those at risk, should conduct monitoring, in order to improve the monitoring and control of the CCPP. The situation in the East African countries and Middle East Asia is very different. In these counties, CCPP is considered to be prevalent and is often recognized as a major threat to goat herding, but the prevention of diseases by costeffective vaccines is partial. The Mccp saponin antigen-based CCPP vaccines are very successful and confer immunity that is relatively long-lived, but very expensive. As a result, new measures are urgently geared towards the production of cheap, qualitycontrolled vaccines. The eradication of CCPP would be highly difficult due to its wide distribution and insidious countryside. Antibiotic therapies, combined with medical prophylaxis, can only be prescribed as part of well-designed prevention strategies. The chosen strategy for regulating CCPP should, however, still be preventive vaccination. FAO, EFSA AHAW, and national or regional research stations will also play an important role in future global efforts to counter this evolving and serious challenge to goat farming worldwide by developing successful in order to improve the CCPP's monitoring and control. Re-visiting conventional prophylactic measures focussing on developing novel strain-based or recombinant vaccines using specific antigens (capsular or cellular) should be the most important strategy for controlling the disease worldwide.

\section{Authors' contributions}

Conceived \& designed the experiment: A Kabir, AH Mirani \& M Rasheed, Performed the experiments: DK Bhuptani, HA Kaleri, MB Abro, Analyzed the data: ZA Bozdar, R Kumar, S Kakar \& AW Solangi, Wrote the paper: M Rasheed, RR Kaleri, MC Khatri \& IB Knadhro.

\section{References}


1. OIE (World Organization for Animal Health) (2017). Manual of Diagnostic Tests and Vaccines for Terrestrial Animals 2017. http://www.oie.int/en/internationalstandard-setting/ terrestrialmanual/access-online.

2. OIE (2014). World Organization for Animal Health - contagious caprine pleuropneumonia. In Manual of Diagnostic Tests and Vaccines for Terrestrial Animals, Chapter 2.7.5. Paris:

3. Massa D, Wakenell AJ \& Brooks D (1992). Mycoplasmas of goats and sheep. J of Vet Diagn Invest 4(4): 101-113.

4. Yatoo MI \& Kanwar MS (2016). Management of common diseases of livestock in Changthang Krishi Vigyan Kendra (KVK) Nyoma pamphlet. pp. 116.

5. Parray OR, Yatoo MI, Muheet M, Bhat RA, Malik HU, Bashir ST \& Magray SN (2019). Seroepidemiology and risk factor analysis of contagious caprine pleuropneumonia in Himalayan Pashmina Goats. Small Rumin Res 1(1): 23-36.

6. Lorenzon S, Wesonga $\mathrm{H}$, Ygesu L, Tekleghiorgis T, Maikano Y, Angaya M, Hendrikx P \& Thiaucourt F (2002): Genetic evolution of Mycoplasma capricolum subsp. capripneumoniae strains and molecular epidemiology of contagious caprine pleuropneumonia by sequencing of locus H2. J of Vet Micro 85(4): 111-123.

7. MacOwan KJ \& Minnette JE (1976). A Mycoplasma from acute contagious Caprine pleuropneumonia in Kenya. Trop Animal Health Prod 8(3): 91-96.

8. Deeb EL, Almujallia A, Eljaliia I, Elmoslemany A \& Fayez M (2017): Contagious caprine pleuropneumonia: The first isolation and molecular characterization of Mycoplasma capricolum subsp. capripneumoniae in the Kingdom of Saudi Arabia. Acta Tropica 168(7): 74-79.

9. Rurangirwa FR, Masiga WN, Muriu DN, Muthomi E, Mulira G, Kagumba M \& Nandokha E (1981). Treatment of contagious caprine pleuropneumonia. Trop Anim Health Prod 13(3): 177-182.

10. Arif A, Schulz J, Thiaucourt F, Taha A \& Hammer S (2007). Contagious caprine pleuropneumonia outbreak in captive wild ungulates at $\mathrm{Al}$ Wabra wildlife preservation, state of Qatar. JZoo Wildl Med 38(1): 93-96.

11. Chaber A, Lignereux L, Qassimi M, Saegerman C, Manso-Silva'n L, Dupuy V \& Thiaucourt F (2014). Fatal transmission of contagious caprine pleuropneumonia to an Arabian oryx (Oryx leucoryx). Vet. Microbiol 173(8):156-159.

12. McMartin DA, MacOwan KJ \& Swift LL (1980). A century of classical contagious pleuropneumonia: fromo original description to etiology. British Vet $J$ 136(3): 507-515.

13. Edward DGF (1953). Organisms of the pleuropneumonia group causing disease in goats. Vet Record 65(9): 873-875.

14. Jonas AM \& Barber TI (1969). Mycoplasma mycoides var. capri isolated from a goat in Connecticut. J of Infec Dis 119(1): 126-131.

15. Fisher A, Shapiro B, Muriuki C, Heller M, Schnee C, Bongcam-Rudloff E, Vilei EM, Frey J \& Jores J (2012). The origin of the Mycoplasma cluster coincides with the domestication of ruminants. PLoS One 36150.

16. Nicholas R \& Churchward C (2012). Contagious Caprine Pleuropneumonia: New Aspects of an old disease. Transbound Emerg Dis 59(7): 189-196.

17. Quinn PJ, Markey BK, Leonard FC, Fitz PES, Fanning S \& Hartigan PJ (2011). Veterinary Microbiology and microbial disease. 2nd edition. John Wiley \& Sons 
Ltd. Chichester, West Sussex, UK. pp. 318-324.

18. Leach RH, Ernø H \& MacOwan KJ (1993) Proposal for designation of F38type caprine mycoplasmas as Mycoplasma capricolum subsp. capripneumoniae subsp. Nov. and consequent obligatory relegation of strains currently classifi ed as $\mathbf{M}$. capricolum Tully, Braile, Edward, Theodore and Ernø 1974 to an additional new subspecies M. capricolum subsp. capricolum subsp. Nov. Intern J of Syst Bact 43(67): 603-605.

19. Thiaucourt F (2012). Contagious caprine pleuropneumonia. In: Manual of diagnostic tests and vaccines for terrestrial animals: (mammals, birds and bees). OIE. Paris: OIE, pp. 995-1007. ISBN 978-92-9044-878-5.

20. Houshaymi B, Tekleghiorghis T, Wilsmore AJ, Miles RJ \& Nicholas RAJ (2002) Investigations of outbreaks of contagious caprine pleuropneumonia in Eritrea. Trop Anim Health Prod 34(25): 383-389.

21. Bölske G, Johansson KE, Heinonen R, Panvuga PA \& Twinamasiko E (1995). Contagious caprine pleuropneumonia in Uganda and isolation of Mycoplasma capricolum subspecies capripneumoniae from goats and sheep. Vet Rec 137(23): 594-598.

22. Shiferaw G, Tariku S, Ayelet G \& Abebe $\mathrm{Z}$ (2006). Contagious caprine pleuropneumonia and Mannheimia haemolytica associated acute respiratory disease of goats and sheep in Afar Region, Ethiopia. Rev Sci Ttech Off Int Epiz 25(3): 1153-1163.

23. Mbyuzi A, Erick V, Komba E, Kimera S \& Kambarage D (2014). Seroprevalence and associated risk factors of peste des petitsruminants and contagious caprine pleuro-pneumonia in goats and sheep in the Southern Zone of Tanzania. Prev Vet Med 116(87): 138-144.

24. Suryawanshi S, Tembhurne P, Gohain S, Kesharkar J, Tumlam U \& Ingle V (2015). Sero-prevalence of contagious caprine pleuropneumonia in small ruminants in Maharashtra. Indian $J$ Vet Sci Biotech 10(4): 73-74.

25. Rurangirwa F \& McGuire T (1996). Contagious caprine pleuropneumonia: Diagnosis and control. Online retrieved from, www.fao.org/wairdocs /ilri/x5473b /x5473- b11.htm.

26. Radostits OM, Blood DC \& Gay CC (1994). Diseases caused by Mycoplasma species. In: Veterinary Medicine, 8th ed. ELBS Govt. of UK, Bailliere Tindall, and London: pp. 908-925.

27. Thiaucourt F, Bölske G, Leneguersh B, Smith D \& Wesonga H (1996). Diagnosis and control of contagious caprine pleuropneumonia. Rev Sci Tech Off Int Epiz 15(4): 1415-1429.

28. Tigga M, Choudhary B, Ghosh R \& MaliK P (2014). Mycoplasmosis: An emerging threat to developing livestock industry. Int $J A d v$ Res 2(1): 558- 564.

29. Niclholas R, Ayling R \& McAuliffe L (2008). Mycoplasma diseases of ruminants. Wallingford, $\mathrm{UK}$ : $\mathrm{CAB}$ International. pp. 114-131.

30. Chernova OA, Medvedeva ES, Mouzykantov AA, Baranova NB \& Chernov VM (2016). Mycoplasmas and their antibiotic resistance: the problems and prospects in controlling infections. Acta Nat 8(7): 24-34.

31. OIE. (2008). Contagious Caprine Pleuropneumonia in Terrestrial Manual. Chapter 2.7.6. pp. 1000-1012.

32. Mondal D, Pramanik AK \& Basak DK (2004). Clinico- Haematology and pathology of Caprine Mycoplasma pneumonia in rain fed tropics of West Bengal. Small Rum Res 51(45): 285-295. 
33. Wesonga HO, Bölske G, Thiaucourt F, Wanjohi C \& Lindberg R (2004). Experimental Contagious Caprine Pleuropneumonia: A Long Term Study on the Course of Infection and Pathology in a Flock of Goats Infected with Mycoplasma capricolum subsp. Capripneumoniae. Acta Vet Scand. 45(51): 167-179.

34. Hernandez L, Lopez J, Jacques MS, Lourdes O, Jorge A \& Katherine $\mathrm{H}$ (2006). Mycoplasma mycoides subsp. capri associated with goat respiratory disease and high flock mortality. Can Vet J. 47(4): 366-369.

35. Gelagay A, Teshale S, Amsaluc W \& Esayas G (2007). Prevalence of contagious caprine pleuropneumonia in the Borana pastoral areas of Ethiopia. Small Rum Res 70(53): 131-135.

36. OIE (World Organization for Animal Health) (2017). Manual of Diagnostic Tests and Vaccines for Terrestrial Animals 2017. http://www.oie.int/en/internationalstandard-setting/ terrestrialmanual/access-online.

37. OIE (2009). Contagious caprine pleuropneumonia. Online retrieved from: http://www.oie.int/fHome/eng/Animal Health_in_the_World/docs/pdf/CONTA GIOUS_CAPRINE_PLEUO_FINAL.pd f.

38. Hernandez L, Lopez J, Jacques MS, Ontiveros L, Acosta J \& Handel K (2006). Mycoplasma mycoides subsp. capri associated with goat respiratory disease and high flock mortality. Can Vet $J$ 47(33): 366-369.

39. IBAR AU (2015). Standard methods and procedures (SMPs) for contagious caprine pleuropneumonia (CCPP) in the Greater Horn of Africa, Nairobi. 20.

40. Wamwayi HM, Wafula JS, Litamoi JK \& Nandokha EN (1989). Detection of antibody to mycoplasma F38 in goat sera by an enzyme-linked immunosorbent assay. Trop Anim Health Prod 21(1): 4349.

41. Thiaucourt F, Bölske G, Libeau G, LeGoff C \& Lefèvre P (1994). The use of monoclonal antibodies in the diagnosis of contagious caprine pleuropneumonia (CCPP). Vet Microbiol. 41(3): 191-203.

42. Rurangirwa FR, McGuire TC, Kibor A \& Chema S (1987b). A latex agglutination test for field diagnosis of contagious caprine pleuropneumonia. Vet Rec 121(9).

43. March J, Gammack C \& Nicholas R (2000). Rapid Detection of Contagious Caprine Pleuropneumonia Using a Mycoplasma capricolum subsp. capripneumoniae Capsular Polysaccharide-Specific Antigen Detection Latex Agglutination Test. J Clin Microbiol 38(11): 4152-4159.

44. Woubit S, Lorenzon S, Peyraud A, Silván ML \& Thiaucourt F (2004) A specific PCR for the identification of Mycoplasma capricolum subsp. capripneumoniae, the causative agent of contagious caprine pleuropneumonia (CCPP). Vet Microbiol 104(77): 125-132.

45. Heldtander M, Wesonga H, BoÈlske G, Pettersson B \& Johansson K (2001). Genetic diversity and evolution of Mycoplasma capricolum subsp. capripneumoniae strains from eastern Africa assessed by $16 \mathrm{~S}$ rDNA sequence analysis. Vet Microbiol 78(67): 13-28.

46. Verma R (2000). Glimpses of Indian Veterinary Science, Daya Publishing House Delhi.

47. Mehra S, Rana R, Mondal A, Kumar V, Kumar A, Vihan VS \& Sharma MC (2009). Comparative evaluation of antibody response in goats vaccinated with Saponin and Saponin-Algel Mycoplasma mycoides subsp. capri vaccines by Enzyme Linked 
Immunosorbant Assay. Ind $J$ of Anim Sci 79(66): 1127-1129.

48. Srivastava NC, Sikdar A \& Srivastava SK (1990). Preliminary trials on the development of an attenuated vaccine against caprine pleuropneumonia. Ind $J$ of Anim Sci 60(57): 645-647.

49. Rana R, Srivastava NC \& Singh VP (1999). Monitoring of humoral response in goats immunized with killed Mycoplasma mycoides subsp. capri saponin vaccine by slide agglutinatioin and latex agglutination tests. Ind $J$ of Comp Micro Immun and Infec Dis 20(12): 39-41.

50. Kumar A, Srivastava NC \& Singh VP (2009). Immunogenicity of Mycoplasma agalactiae saponin vaccine in mice. Ind $J$ of Comp Micro, Immun and Infec Dis 30(51): 61-62.

51. Yatoo MI, Kanwar MS, Kubrevi SS, Shabir M, Dar R \& Angmo K (2014). Safeguarding a national asset: a review on problems faced by pashmina farmers in Changthang and their amelioration. Ind J of Anim Sci 84(77): 1251-1255.

52. Yatoo MI \& Kanwar MS (2016) Management of common diseases of livestock in Changthang. Krishi Vigyan Kendra (KVK) Nyoma pamphlet. pp. 116.

53. Yatoo M, Parray OR, Mir MS, Qureshi S, Kashoo ZA, Nadeem M, Bhat RA, Mr Tufani NA F, Kanwar MS, Rana R \&
Dhama K (2018). Mycoplasmoses in small ruminants in India: a review. $J$ Exp Bio Agri Sci 6(2): 264-281.

54. Ozdemir U, Loria GR, Godinho KS, Samson R, Rowan TG, Churchward C, Ayling RD \& Nicholas RA (2006). Effect of danofloxacin (Advocin A180) on goats affected with contagious caprine pleuropneumonia. Trop Anim Health Prod 38(7-8): 533-540.

55. Ozdemir U, Loria GR, Godinho KS, Samson R, Rowan TG, Churchward C, Ayling RD \& Nicholas RA (2006). Effect of danofloxacin (Advocin A180) on goats affected with contagious caprine pleuropneumonia. Trop Anim Health Prod 38(7-8): 533-540.

56. FAO (2017). Food and Agriculture Organisatio: contagious caprine pleuropneumonia.

https://www.cabi.org/isc/data sheet/88092.

57. IBAR AU (2015). Standard methods and procedures (SMPs) for contagious caprine pleuropneumonia (CCPP) in the Greater Horn of Africa, Nairobi. pp. 20.

58. OIE [accessed 2018 Jun22]. http://www.oie.int/fileadmin/ Home/eng/Health_standards/tahm/2.07.0 5_CCPP.pdf.

59. Edward DGF (1953). Organisms of the pleuropneumonia group causing disease in goats. Vete Rec 65(76): 873-875. 